\title{
Representatividade negra no executivo municipal: impacto da posição partidária para a eleição de mulheres e homens negros nas prefeituras da Bahia
}

\author{
Cleber Lázaro Julião Costa' ${ }^{10}$
}

Universidade do Estado da Bahia

\section{Dossiê | Dossier | Dosier \\ DOI do artigo: 10.22481/odeere.v6i01.8525 RESUMO}

O presente trabalho traz um estudo do perfil dos (as) 417 prefeitos (as) eleitos no estado da Bahia nas eleições de 2016 pelos critérios de cor/raça e gênero. A partir desta definição, busca compreender qual o compromisso que os partidos políticos vitoriosos têm com a agenda antirracista e de igualdade de gênero de modo a compreender se mulheres e homens negros têm à disposição conteúdo propositivo dos partidos que apoiem pautas defendidas pelo movimento Negro e Feminista. A análise dos dados revela que a Bahia é governada majoritariamente por homens, e brancos (as) lideram a corrida de forma desproporcional já que sequer correspondem a $20 \%$ da população do estado. Por outro lado, a participação de mulheres e homens negros, apesar de representarem maioria dos eleitos, não significa corresponder automaticamente a uma associação objetiva da pauta antirracista e de igualdade de gênero dada às vinculações partidárias que escolheram.

Palavras-chave: Representação partidária, Raça, Gênero, Município

\section{Black representativity at Mayor Office: the impact of the parties' ideology for the election of black man and women ABSTRACT}

The current article brings a study of the mayors profile elected in the state of Bahia at the 2016 elections by color/race and gender criteria. From such definition, it seeks to aware what the political parties commitment is for the anti-racism and gender equality agenda regarding if women and man blacks have been supported by those political parties. The data analysis reveals that the Bahia state was ruled by men, and whites lead the race disproportionally despite they just represent less of $20 \%$ of bahianese population. For the other side, women and man black political participation does not mean automatically that they are engaged of to defend the anti-racism and gender equality agenda due their political parties' choices.

Keywords: History teaching; Whiteness; Racism; Sexism; Mandatory Curricular Internships.

\section{Submetido em: 27 de abr. de 2021 | Aceito em: 15 de jun. de 2021}

\section{INTRODUÇÃO}

Representatividade e participação política passaram a compor o vocabulário das ciências humanas à medida que segmentos sociais marginalizados conseguiram amplificar suas vozes pela luta de direito. Este fenômeno fruto do processo civilizatório de ampliação do sentido de humanidade tratou de pôr em xeque a perspectiva ontológica de um sujeito universal pela medida do ocidental,

\footnotetext{
1 Doutor em Sociologia pelo Instituto de Estudos Sociais e Políticos da Universidade do Estado do Rio de Janeiro, mestre em Sociologia pelo Instituto Universitário de Pesquisas do Estado do Rio de Janeiro da Universidade Cândido Mendes e bacharel em Direito pela Universidade Católica do Salvador. É professor adjunto da Universidade do Estado da Bahia da disciplina Ciência Política no Colegiado de Ciências Sociais do Departamento de Educação, Campus Salvador. Tem experiência na área de relações raciais, direitos humanos, ações afirmativas. E-mail: clcosta@uneb.br
} 
Costa, C. L. J., Representatividade negra no executivo municipal: impacto da posição partidária para a eleição de mulheres e homens negros nas prefeituras da Bahia. ODEERE, vol. 6, no. 1 , jan./jun., p. 183-208, 2021. https://doi.org/10.22481/odeere.v6i01.8525

do patriarcado e da branquitude, por exemplo.

A igualdade formal legatária da ideia de que a sua garantia daria condições ao exercício político viu-se objeto de questionamento ao enfrentar os indicadores de desigualdades socioeconômicas de negras e negros, cuja realidade, em comparação com os não negros era e ainda é de maior vulnerabilidade². As inúmeras desvantagens de acesso a recursos básicos, como saúde, educação, trabalho digno, entre outros, implicam também no déficit de participação e representação política. Esta situação foi negligenciada pela Ciência Política e precisa ser reparada.

É com esse propósito que o presente artigo pretende contribuir para a discussão sobre a representatividade de mulheres e homens negros na política partidária do estado Bahia. Com efeito, este estudo analisa a relação entre a agenda antirracista e pela igualdade de gênero com os posicionamentos dos partidos políticos em que candidatos (as) negros foram eleitos (as) nas eleições de 2016, cujo mandato se encerrou em 31 de dezembro de 2020.

Qual o impacto da ideologia partidária para a eleição de políticos (as) negros (as) nas campanhas eleitorais de 20216? A partir da análise dos manifestos, diretrizes e propostas dos partidos é possível afirmar de que candidatos (as) negros e negras aderiram à agenda antirracista e de igualdade de gênero como componente da plataforma política de campanha?

O presente trabalho está divido em três seções, além da introdução e conclusão, em que estão trabalhados os seguintes pontos: apresentação dos dados com a respectiva distribuição de prefeitos (as) e os seus respectivos partidos políticos; desafios da escala direita-esquerda frente à agenda antirracista e de igualdade de gênero; e análise da combinação dos dados pela medida de adesão à agenda de movimentos negros e feminista.

A presente temática merece amplo debate e desenvolvimento de pesquisas que iluminem a realidade sobre a participação política de grupos historicamente marginalizados. Como espaços necessários para ocupação do poder político institucional materializado em cargos, cujo acesso é feito pelo voto popular, os partidos políticos precisam ser estudados em relação ao espaço que disponibilizam

2 PAIXÃO, Marcelo. A lenda da modernidade encantada: por uma crítica ao pensamento social brasileiro sobre as relações raciais e o projeto de estado-nação. Curitiba: CRV. 2014 
Costa, C. L. J., Representatividade negra no executivo municipal: impacto da posição partidária para a eleição de mulheres e homens negros nas prefeituras da Bahia. ODEERE, vol. 6, no. 1, jan./jun., p. 183-208, 2021 . https://doi.org/10.22481/odeere.v6i01.8525

a negros e negras.

Os partidos correspondem, assim, a um espaço de exercício político necessário. Em uma sociedade marcada por assimetrias tão expressivas, quaisquer mudanças com vistas a reduzi-las na esfera da democracia passam pela participação igualitária nos espaços partidários de modo que vozes e atores/atrizes defensores das pautas antirracistas e pela igualdade de gênero possam ter o seu espaço, influenciando no desenvolvimento de políticas públicas. Pretende com este artigo, pois, contribuir para o desenvolvimento de estudos com esta temática da representação e diversidade para que se possa pensar em estratégias e proposições que visem efetividade na representação de gênero e racial.

\section{ELEIÇÃO 2016: DISTRIBUIÇÃo RACIAL DOS PREFEITOS (AS) ELEITOS (AS) E SEUS RESPECTIVOS PARTIDOS NO ESTADO DA BAHIA}

O levantamento do perfil racial de prefeitos (as) eleitos (as) nas eleições de 2016 utilizou do critério da autoidentificação dos (as) candidatos (as) graças à inclusão desta variável em 2014. Antes deste ano, a possibilidade de identificação da cor/raça de candidatos (as) a quaisquer cargos eletivos no Brasil dependia de hercúleo esforço de investigação pelo critério de heteroidentificação dos pesquisadores (as) ${ }^{3}$.

Assim, os dados levantados correspondem à forma como candidatos (as) se auto identificam em relação à cor/ raça. Neste sentido, o critério 4 utilizado para

\footnotetext{
${ }^{3}$ CAMPOS, Luiz Augusto; MACHADO, Carlos. A cor dos eleitos: determinantes da sub-representação política dos não brancos no Brasil. Brasília: Rev. Bras. Ciência Política, n. 16. 2015.

4 Petruccelli e Saboia organizaram publicação para Instituto Brasileiro de Geografia e Estatística estudo intitulado Características Étnico- raciais da população: classificações e identidades, no ano de 2013, em que consta o histórico dos censos e adoção do critério cor/raça. No Brasil, a definição sobre os critérios de identificação racial sofreu mudanças significativas ao longo da história. $O$ primeiro censo, realizado em 1872, na classificação por raças, optou pelo uso das terminologias branco, preto, pardo e caboclo, por estarem disseminadas no tecido social, permitindo maior uniformidade para a pesquisa. O de 1890 usou branco, preto, caboclo e mestiço. Esta última identificação consorciou à aparência física a ascendência da pessoa entrevistada. Mestiço correspondia à denominação para as pessoas cujos pais eram pretos (as) e brancos (as). O uso desta terminologia representava a assunção do sentido de branqueamento que significava a diluição do sangue negro pelo cruzamento com os brancos que aqui estavam além dos contingentes migratórios, cujo efeito foi a redução gradual da população preta no país. O retorno do uso da categoria em 1940 (as de 1900 e 1920 não foram usadas, e, em 1910 e 1930, não houve censo), sendo a expressão "raça" substituída por "cor", teve o uso de branco, preto e amarelo. A partir deste censo, a cor adquiriu o critério referência para as representações ambíguas, produto do momento em que o discurso de eugenia, que hegemonizou a retórica de projeto nacional sobretudo na $1^{a}$ República, deu espaço para um projeto de unidade nacional. Os censos de 1950 e 1960 reincorporam o grupo pardo à categorização de "cor". No de 1970, a variável "cor" foi
} 
Costa, C. L. J., Representatividade negra no executivo municipal: impacto da posição partidária para a eleição de mulheres e homens negros nas prefeituras da Bahia. ODEERE, vol. 6, no. 1 , jan./jun., p. 183-208, 2021. https://doi.org/10.22481/odeere.v6i01.8525

discriminação das variáveis é o do Instituto Brasileiro Geográfico de Estatística (2011 e 2013), IBGE, que vem adotando o somatório de pretos e pardos para o conjunto de negros, além de branco, amarelos e indígenas.

No levantamento realizado, apenas variáveis preto, pardo e branco foram usadas, pois indígenas e amarelos representavam $0,26 \%$ da população de prefeitos (as). Em verdade, não houve registro de prefeitos indígenas, e a representação dos amarelos ficou limitada a de uma pessoa apenas do sexo masculino.

O estado da Bahia é composto de 417 municípios distribuídos em sete mesorregiões onde habitavam, com base no censo de 2010 do IBGE$^{5}$, por volta de 10milhões de eleitores nas eleições de 2016. Os (as) prefeitos (as) eleitos (as) da cor branca chegaram na frente, como se vê na tabela 1 abaixo:

Tabelal:

\section{Prefeitos e Prefeitas - mandato 2017-2020 "cor ou raça"}

\begin{tabular}{lrrr}
\multicolumn{1}{c}{ VARIÁVEL } & NÚMERO & PREFEITOS & TOTAL ELEITOS (AS) \\
PRETOS (AS) & 14 & $3 \%$ & $3 \%$ \\
PARDOS (AS) & 197 & $47 \%$ & $47 \%$ \\
BRANCOS (AS) & 205 & $49 \%$ & $49 \%$ \\
TOTAL & 416 & $100 \%$ & $100 \%$
\end{tabular}

Fonte: Costa, 2021.

Como se vê, apesar da vitória de brancos (as), prefeitos (as) pardos possuem expressiva representatividade no processo eleitoral. A lanterna, de fato, fica com os pretos, cujo número de mandatos de chefes do executivo não chega a $15 \mathrm{em}$ números absolutos nos municípios no estado da Bahia. Em valores percentuais, prefeitos (as) brancos (as) correspondem a $49 \%$, pardos (as) a $47 \%$ e pretos (as) $3 \%$ da população analisada entre homens e mulheres.

Por outro lado, a análise ganha outro contorno se há agregação das variáveis pardo e preto. A representação de políticos negros demonstra uma pequena vantagem em relação ao grupo branco. Metade dos (as) prefeitos (as) eleitos (as)

excluída. No de 1980, a variável deixa ser trabalhada na perspectiva censitária e foi deslocada para pesquisa amostral. Em 1991, a categoria indígena foi acrescentada e a pergunta passou a ser de "raça ou cor". Nos de 2000 e 2010, a houve mudança da ordem da pergunta para "cor ou raça", bem como sendo parte do questionário censitário e não mais amostral. No de 2010, pela primeira vez, pessoas indígenas foram indagadas a respeito de sua etnia e língua falada.

${ }^{5}$ Cf. site do IBGE https://cidades.ibge.gov.br/brasil/ba/panorama acessado em 20 de abril de 2021. 
Costa, C. L. J., Representatividade negra no executivo municipal: impacto da posição partidária para a eleição de mulheres e homens negros nas prefeituras da Bahia. ODEERE, vol. 6, no. 1 , jan./jun., p. 183-208, 2021. https://doi.org/10.22481/odeere.v6i01.8525

em 2016 declararam-se, em tese negros, entre homens e mulheres.

Essa vantagem está ainda abaixo da taxa total da população negra no estado, por volta de $81,1 \%$, enquanto a população branca $18,1 \%$, com base nos dados da PNAD-Contínua 20186. Isto significa que os brancos, apesar de serem minoria do estado, abocanham quase $50 \%$ de todos os municípios. Este quadro revela potenciais desvantagens em candidaturas negras que precisam ser analisadas.

$\mathrm{Na}$ distribuição das prefeituras pelo sexo, vê-se de modo contundente a hegemonia masculina no cargo do executivo municipal. São 361 municípios governados por homens, como se vê na tabela 2 :

Tabela 2: Prefeitos eleitos, mandato 2017-2020, "cor ou raça"

Prefeitos eleitos mandato 2017-2020 "cor ou raça"

VARIÁVEL

PRETOS

PARDOS

BRANCOS

TOTAL
NÚMERO

14

178

168

360
PREFEITOS

TOTAL ELEITOS (AS)

$4 \%$

$3 \%$

$43 \%$

$40 \%$

$100 \%$

Fonte: Costa, 2021.

Na tabela acima, constam apenas os homens pardos, pretos e brancos, razão pela qual a conta é 360. A única pessoa autodeclarada de cor/raça amarela é homem também.

Vejamos agora a situação de performance eleitoral interseccionando a variável cor ou raça com a de gênero das (os) candidatas (os). Na tabela 3, é possível conferir a participação feminina na população de chefas do executivo municipal no estado da Bahia pela relação sexo e cor ou raça.

\footnotetext{
6 As tabelas do IBGE da Pesquia por Amostra de Domicílio podem ser acessadas pelo site https://www.ibge.gov.br/estatisticas/sociais/populacao/25844-desigualdades-sociais-por-cor-ouraca.html? =\&t=resultados acessada no dia 11/04/21.
} 
Costa, C. L. J., Representatividade negra no executivo municipal: impacto da posição partidária para a eleição de mulheres e homens negros nas prefeituras da Bahia. ODEERE, vol. 6, no. 1 , jan./jun., p. 183-208, 2021. https://doi.org/10.22481/odeere.v6i01.8525

Tabela 3- Prefeitas eleitas, mandato 2017-2020, "cor ou raça"

\section{Prefeitas eleitas mandato 2017-2020 "cor ou raça"}

417

VARIÁVEL

NÚMERO

PREFEITAS

TOTAL ELEITOS (AS)

$\begin{array}{lrcr}\text { PRETAS } & 0 & 0 \% & 0 \% \\ \text { PARDAS } & 19 & 34 \% & 5 \% \\ \text { BRANCAS } & 37 & 66 \% & 9 \% \\ \text { TOTAL } & 56 & 100 \% & 13 \%\end{array}$

Fonte: Costa, 2021.

No estado da Bahia, a população feminina apurada no censo de 2010 representava 50,93\%, enquanto a masculina $49,07 \%$ de mais de 14 milhões de habitantes. Dos 417 municípios baianos, apenas 56 eram administrados por prefeitas para o mandato 2017-2020. A representação feminina correspondia a apenas $13 \%$ nas prefeituras, ilustrando uma condição de baixíssima representatividade.

A baixa representatividade feminina em esferas de poder está presente também nos parlamentos brasileiros, onde a taxa de ocupação não chega 9\% das cadeiras em disputa7. Tal situação revela um inequívoco quadro de desvantagem de competição.

No caso da representatividade de mulheres negras, a situação é bastante grave. As mulheres negras ocupavam cargos do executivo municipal em 19 municípios sendo todas pardas. Não havia no estado da Bahia sequer uma prefeita que tivesse se autodeclarado preta na eleição de 2016. Na comparação entre prefeitas pardas e brancas, estas correspondiam a $66 \%$ do número total de mulheres eleitas, enquanto as pardas correspondiam a 34\%. Apesar de representarem a maioria da população baiana, seja em relação aos homens, seja em relação ao cômputo de mulheres, as negras (pretas e pardas) estavam super sub representadas, sendo que as pretas eram invisíveis no processo competitivo

7 SACCHET, Tereza. Partidos políticos e (sub) representação feminina: um estudo sobre recrutamento legislativo e financiamento de campanhas. In PAIVA, Denise (org.) Mulheres, política e poder. Goiânia: Cânone. 2011 pp. 159-186. 
Costa, C. L. J., Representatividade negra no executivo municipal: impacto da posição partidária para a eleição de mulheres e homens negros nas prefeituras da Bahia. ODEERE, vol. 6, no. 1 , jan./jun., p. 183-208, 2021. https://doi.org/10.22481/odeere.v6i01.8525

eleitoral partidário por uma chefia do executivo municipal no estado da Bahia.

Em relação à filiação partidária nas eleições, prefeitas e prefeitos foram eleitos por 23 legendas diferentes. Dos atuais 30 partidos políticos registrados atualmente no Tribunal Superior do Trabalho, três que obtiveram êxito nas prefeituras baianas foram incorporados: PPS, virou Cidadania, PRP não superou a cláusula de barreira em 2018 e foi incorporado ao Patriota em 2019. O PTN criou o Podemos em 2017.

A distribuição dos partidos demonstra uma expressiva dispersão. São legendas que se colocam à direita, à esquerda e ao centro do jogo político. No gráfico 1 , estão dispostas as legendas que elegeram prefeitos (as) na Bahia

Gráfico 1: Legendas exitosas na Bahia

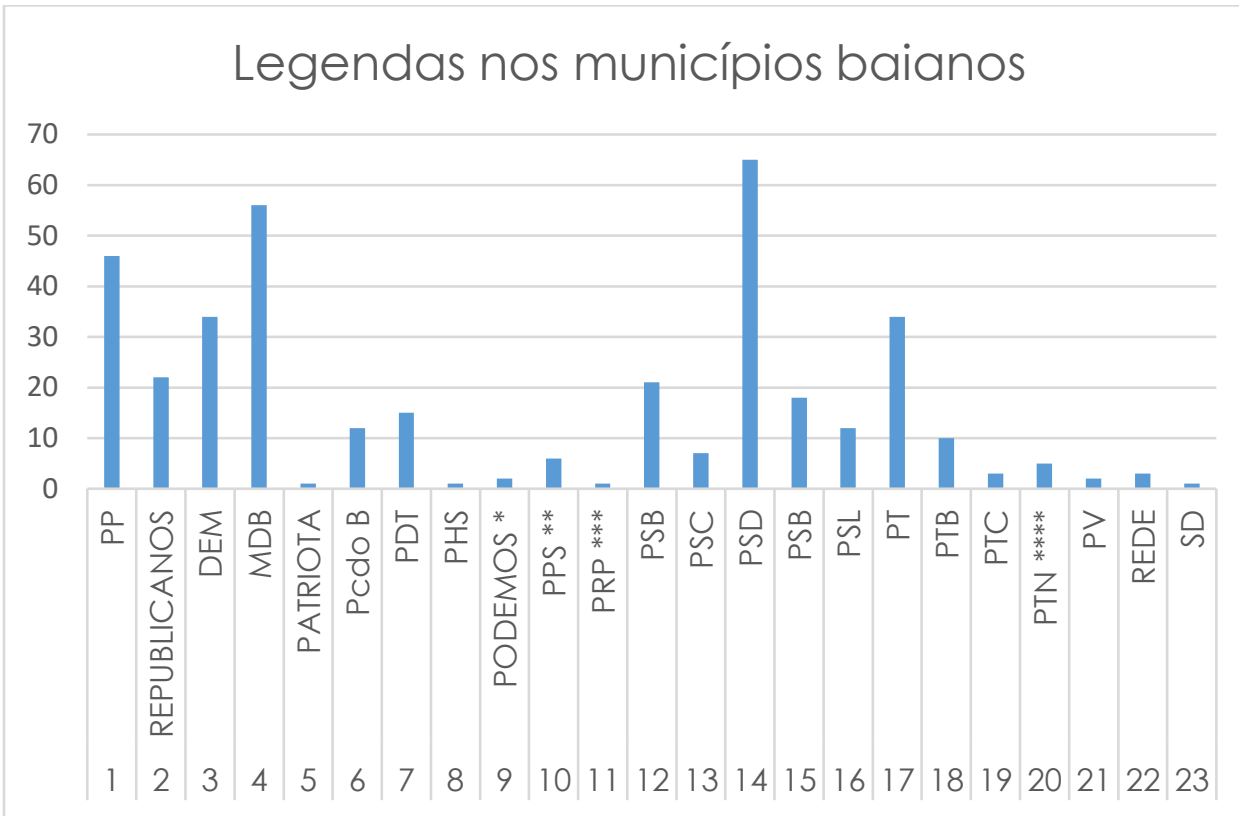

FONTE: Costa, 2021.

Do cruzamento das legendas partidárias exitosas com a identificação racial, é possível constatar igualmente uma pulverização das legendas para a população branca, que possui representatividade em todos os partidos, como se vê na tabela 4

Tabela 4: Legendas por cor ou raça- homens e mulheres

\begin{tabular}{|l|r|r|r|r|}
\hline \multicolumn{1}{|c|}{ PARTIDOS } & BRANCO (A) & PARDO (A) & PRETO (A) & \multicolumn{2}{c|}{ TOTAL } \\
\hline DEM & 18 & 29 & 2 & 49 \\
\hline MDB & 25 & 18 & & 43 \\
\hline PC do B & 7 & 7 & & 14 \\
\hline PDT & 9 & 11 & & 20 \\
\hline PP & 28 & 22 & 3 & 53 \\
\hline PODEMOS & 4 & 1 & 1 & 6 \\
\hline REPUB & 14 & 11 & 2 & 27 \\
\hline PSB & 15 & 7 & 1 & 23 \\
\hline
\end{tabular}


Costa, C. L. J., Representatividade negra no executivo municipal: impacto da posição partidária para a eleição de mulheres e homens negros nas prefeituras da Bahia. ODEERE, vol. 6, no. 1 , jan./jun., p. 183-208, 2021 . https://doi.org/10.22481/odeere.v6i01.8525

\begin{tabular}{|l|r|r|r|r|}
\hline PSC & 3 & & & 3 \\
\hline CIDADANIA & 3 & 4 & & 7 \\
\hline PSD & 43 & 32 & 2 & 77 \\
\hline PSDB & 7 & 11 & & 18 \\
\hline PSL & 6 & 4 & 1 & 11 \\
\hline PT & 15 & 22 & 2 & 39 \\
\hline PTB & 4 & 6 & & 10 \\
\hline PTC & 1 & & & 1 \\
\hline PTB & 2 & 6 & & 8 \\
\hline AVANTE & 1 & & & 1 \\
\hline PV & 1 & 1 & & 2 \\
\hline SD & 1 & & & 3 \\
\hline REDE & 2 & 1 & & 416 \\
\hline \multicolumn{1}{|c|}{ TOTAL } & 209 & 193 & 14 & \\
\hline
\end{tabular}

Pardos (as) possuem representatividade proporcional em relação aos brancos (as). Já Pretos apenas possuem representatividade em sete partidos, lembrando que apenas homens fazem parte deste grupo.

Da correlação legenda/cor ou raça, chama atenção que não existe uma objetiva diferença de adesão partidária à variável "cor ou raça". Pessoas pretas e pardas aderem a partidos de todas as naturezas. Este fenômeno também é percebido na condição de gênero, traduzindo, assim, uma situação que exige uma análise articulada entre a competição eleitoral e elementos do pensamento social brasileiro de modo a se chegar a algumas conclusões.

Diante deste mosaico, cuja marca sugere uma ação política generalista em relação ao projeto político, cabe fazer um esforço que permita, na medida do possível, identificar a existência de adesão ao legítimo discurso de inclusão pautado por minorias, em específico para este artigo, a agenda antirracista e de igualdade de gênero. Como agências do processo político competitivo, os partidos devem trazer em suas proposições definição de projeto de poder de modo que a sociedade possa da forma mais objetiva possível fazer suas escolhas. Conhecimento corresponde no sentido proposto ferramenta essencial para $\circ$ exercício cívico consciente.

\section{PARTIDOS POLÍtICOS E OS DESAFIOS DE CLASSIFICAÇÃo PELA ESCALA DIREITA- ESQUERDA}

Uma marca que se consolidou em relação à competição político-partidária 
Costa, C. L. J., Representatividade negra no executivo municipal: impacto da posição partidária para a eleição de mulheres e homens negros nas prefeituras da Bahia. ODEERE, vol. 6, no. 1 , jan./jun., p. 183-208, 2021. https://doi.org/10.22481/odeere.v6i01.8525

ao longo dos anos foi a dicotomia proposta entre direita e esquerda. É quase que automático em debates, seja acadêmico, seja na esfera midiática, seja mesmo informalmente, a articulação de opiniões pela escala de apreensão geral sobre esses dois polos.

No entanto, as mudanças ocorridas com o fim da guerra fria e o colapso do modelo socialista levantaram o debate de que essa diferenciação perdeu importância quanto à constituição de identidade. De fato, a prática política no Brasil trouxe consigo, ao longo desses últimos 30 anos, experiências de um mosaico político configurado pela união de linhas políticas ideologicamente intangíveis. Alianças eleitorais e de governo dos principais partidos, como o PT e PSDB, ilustram de forma fidedigna essa impressão.

A discussão de governabilidade necessária pelas características históricas políticas do Brasil encontra-se como elemento basilar para a realidade brasileira. A política de coalizão corresponderia a forma viabilizada pelos partidos que alcançassem o poder executivo federal9 logo após a promulgação do pacto político na forma de documento constitucional. Em um cenário com interesses tão heterogêneos, uma história de baixa percepção republicana, no que diz respeito ao trato da coisa pública, a cultura política brasileira está, até hoje, impregnada de diversos valores cujo sentido tem sido amoldado no processo civilizatório desses mais de trinta anos de redemocratização.

A propósito, a saída de cena dos militares com a redemocratização pode ser o primeiro quesito no esforço de buscar uma classificação pela escala direitaesquerda da política brasileira. Partidos como PP e DEM, outrora no regime autoritário reunidos no partido Arena, foram aqueles que deram sustentação ao regime autoritário, enquanto PMDB, em linhas gerais, atuou como oposição no sistema bipartidário. Demais partidos viviam na condição de clandestinidade, não atuando, assim, de maneira institucional10.

A redemocratização permitiu que várias legendas ascendessem das sombras

\footnotetext{
${ }^{8}$ Cf. BOBBIO, Norberto. Direita e esquerda: razões e significados de uma distinção política. São Paulo: UNESP, 1995 e GIDDENS, Anthony. Para além da esquerda e da direita: o futuro da política radical. São Paulo: UNESP, 1996.

9 ABRANCHES, Sérgio Henrique. Presidencialismo de coalizão: o dilema instrucional brasileiro. Rio de Janeiro: Dados, vol. 31, n.1, 1988.

10 MADEIRA, Rafael Machado e TAROUCO, Gabriel da Silva. Esquerda e direita no Brasil: uma análise conceitual. R. Pós Ci. Soc., n.15, v.8. 2011.
} 
Costa, C. L. J., Representatividade negra no executivo municipal: impacto da posição partidária para a eleição de mulheres e homens negros nas prefeituras da Bahia. ODEERE, vol. 6, no. 1 , jan./jun., p. 183-208, 2021. https://doi.org/10.22481/odeere.v6i01.8525

impostas pelo regime de exceção cívico-militar que retirou direitos políticos de vários atores. Durante algum tempo, o discurso de direita-esquerda orbitava a partir dessa memória ${ }^{11}$.

O passar do tempo e os arranjos políticos, cujo passo mais significativo foi a parceria entre o PSDB e o DEM, então PFL12, na eleição de Fernando Henrique Cardoso em 1994, exigiram maior complexificação quanto ao entendimento da escala classificatória pelo critério direita-esquerda. Esta exigência tornou-se mais necessária com a ascensão do Partido dos Trabalhadores, em 2002, a partir de uma coalização deste com um leque de partidos que iam desde o PC do B ao partido Republicanos, então, PRB, Partido Republicano Brasileiro.

O cenário complexo quanto à classificação da política brasileira tem como outro ingrediente explicativo a ser incluído a forma de desenvolvimento de política econômica. Durante a polarização PSDB versus PT, entre 1994 e 2014, houve um indicativo sobre a forma de conduzir que cada partido e seus aliados mais próximos promoveriam no desenvolvimento de políticas públicas ${ }^{13}$. A análise desta experiência democrática identificou um dinamismo em que PSDB e PT empreenderam políticas públicas orientadas pelos seus programas e diretrizes doutrinárias possíveis após a estabilidade econômica.

Ao longo dos anos, a representação partidária pela escala direita-esquerda teve o seu protagonismo na condução desses dois partidos. No caso do PSDB, a guinada mais à direita ganhou seus contornos quando na oposição figuras como Geraldo Alckmin ganharam proeminência aliada a um discurso fiscalista, endereçado ao mercado em detrimento da opção de políticas públicas de justiça social protagonizadas pelo Estado. Enquanto do lado da esquerda, o PT conseguiu

\footnotetext{
11 Id.

12 O PFL foi Arena depois PDS. Atualmente é o Democratas.

13 Couto e Arantes (2006) fizerem um levantamento da condução de Emendas Constitucionais propostas pela gestão do PSDB e PT. A partir da perspectiva de que o processo político brasileiro ganhou uma natureza constitucional na medida em que vários compromissos assumidos no pacto político de 5 de outubro de 1988 exigiam definições constitucionais para o desenvolvimento de políticas públicas, os autores perceberam que a maioria das propostas de emendas constitucionais e o seu resultado tratavam de dar- Ihes seguimento. Isto significa que não tinham uma natureza de alteração substantiva do que foi estabelecido como projeto nacional à luz de um projeto de estado de bem estar quando a redução das desigualdades, a redistribuição dos recursos básicos tornaramse relevantes. É bem da verdade que o PSDB em relação ao PT buscou redimensionar o pacto com uma abordagem mais privatista e de criação de agências regulatórias como mediadoras do projeto de consórcio público privado em várias áreas consideradas básicas, como saúde e educação, além de optar pela privatização de várias empresas públicas.
} 
Costa, C. L. J., Representatividade negra no executivo municipal: impacto da posição partidária para a eleição de mulheres e homens negros nas prefeituras da Bahia. ODEERE, vol. 6, no. 1 , jan./jun., p. 183-208, 2021. https://doi.org/10.22481/odeere.v6i01.8525

empreender políticas públicas de amplo alcance combinado com ênfase naquelas de transferência de renda, além de iniciativas de ações afirmativas ${ }^{14}$.

Entretanto, o protagonismo desses dois partidos a nível nacional não significou mudança estrutural na representação políticas nos estados e seus municípios, onde as bases para um pluripartidarismo ganharam tônus ainda com raízes calcadas no patrimonialismo e liderança de famílias tradicionais 15. A movimentação centrípeta de PT e PSDB em direção a legendas desse ethos político sempre ocorreu, buscando dar a governabilidade necessária para o desenvolvimento de seus projetos de governo.

Os partidos que atuam no centro são, historicamente, aqueles que em maior ou menor número estão sempre em colaboração com o partido político que está no poder a nível nacional. Tanto na gestão do PSDB, quanto do PT, vários daqueles partidos deram sustentação política. Representam em sua maioria legendas que se confundem com a própria história política brasileira apesar de não possuírem uma imagem associada às proposições políticas e ideológicas.

A ideia de partidos políticos deve ter como critério importante o projeto de poder. Isto significa que a constituição de um partido político deve ter como desiderato mobilizar o máximo de pessoas com base em suas propostas visando alcançar os cargos eletivos mais altos. Neste sentido, no mínimo a intenção de competir de modo a apresentar sua plataforma de governo é um elemento crucial quanto ao cumprimento desse critério.

Nos casos de vários partidos de centro, esse critério não é atendido. São partidos de penetração municipal expressiva, mas que prescindem de um projeto político clássico de ascensão aos extratos mais altos do sistema político eleitoral visando desenvolver à luz de sua doutrina ideológica políticas públicas. A opção pela posição de coadjuvante busca equilibrar os ônus com os bônus das receitas obrigatórias aos entes municipais, mormente na saúde e na educação.

Os dados trazidos na tabela 4 ilustram bem tanto a baixa representatividade dos dois partidos que ganharam maior destaque político nos últimos 30 anos, PT e PSDB, bem como sobre o peso dos partidos de centro na representação política.

\footnotetext{
14 ALMEIDA, Maria Hermínia Tavares de. Em busca do Centro Perdido. São Paulo: Novo Estudo/CEBRAP. N. 23. 2007.23 15 Id.
} 
Costa, C. L. J., Representatividade negra no executivo municipal: impacto da posição partidária para a eleição de mulheres e homens negros nas prefeituras da Bahia. ODEERE, vol. 6, no. 1 , jan./jun., p. 183-208, 2021. https://doi.org/10.22481/odeere.v6i01.8525

PT e PSDB conseguiram eleger em 2016 apenas 57 prefeitos (13\%) juntos, enquanto PSD, Republicanos, DEM e MDB elegeram 196, sendo que apenas o PSD elegeu 77.

A fragmentação partidária no Brasil é um fenômeno que merece destaque nesses anos de redemocratização. Ela tem sido encontrada a nível nacional e, igualmente, em todos os estados em pesquisas que revelam uma pulverização. Este fenômeno apesar de uma breve queda nas eleições de 2002, voltou a se fortalecer nas eleições seguintes ${ }^{16}$.

A fragmentação partidária representa um grande desafio para análise que visa mapear a influência dos partidos quanto à aferição de representatividade a partir de um discurso antirracista e de igualdade de gênero. Não basta apenas a medir a representatividade de negras e negros nos espaços das legendas partidárias crendo que ela por si própria consiga traduzir-se em iniciativas políticas que permitam a redução das desigualdades seja de gênero, seja racial. É preciso, pois, encontrar conteúdo que, a priori, acolha as pessoas historicamente alijadas da participação política com vistas ao exercício do poder político por meio do voto.

No caso da Bahia, há uma pluralidade de legendas acolhendo negras e negros, brancas e brancos sem uma definição objetiva se a pauta levantada por movimentos sociais negros e feministas fazem parte do conteúdo propositivo para uma sociedade que combata o racismo e os seus efeitos, bem como a desigualdade de gênero, mormente, a sofrida por mulheres negras.

A diversidade partidária encontrada no levantamento de dados na Bahia para eleições de 2016 implica em encontrar caminhos que possam permitir uma análise articulada, respeitando as peculiaridades do sistema partidário vigente no país e a necessidade de iluminar a questão da sub-representação racial e de gênero. Para tal, a opção feita partiu em analisar o conteúdo dos manifestos, diretrizes e propostas dos partidos e qual o nível de articulação da pauta antirracista e de igualdade de gênero.

Essa escolha se deu, pois, a opção pelo uso da escala direita- esquerda parece prejudicada na medida em que a evolução temporal desses anos de democracia pós 1988 ilustrou o percurso dos protagonistas, PT e PSDB, implicou em

16 KINZO, Maria D'Alva G. Partidos, eleições e democracia no Brasil pós 1985. RBCS, vol. 19, n. 54, 2004. 
Costa, C. L. J., Representatividade negra no executivo municipal: impacto da posição partidária para a eleição de mulheres e homens negros nas prefeituras da Bahia. ODEERE, vol. 6, no. 1 , jan./jun., p. 183-208, 2021. https://doi.org/10.22481/odeere.v6i01.8525

arranjos com grupos políticos tradicionais. Estes por sua vez, introduziram em maior ou menor medida algum elemento relativo ao respeito a direitos humanos, ou a igualdade, por exemplo, mas como um todo apresentam propostas generalistas com algum ganho aqui ou acolá do ponto de vista de uma agenda afirmativa que possa aderir à agenda antirracista e de igualdade de gênero. Assim, o factível é encontrar em alguma medida nos documentos partidários cujo conteúdo foi levantado em manifestações relativas à temática racial ou de igualdade de gênero.

\section{AGENDAS ANTIRRACISTA E DE IGUALDADE DE GÊNERO FRENTE ÀS PROPOSTAS DOS} PARTIDOS

O que é agenda antirracista e de igualdade de gênero? Pela perspectiva da Interseccionalidade, que leva em conta que cada tema possui as suas especificidades e simultaneamente pontos próximos, mas que não implica na sobreposição de um tema pelo outro ${ }^{17}$. Para além das categorias que podem indicar identidade ou posição social, raça e sexo, por exemplo, são atributos de poder com efeitos determinantes de acesso aos recursos disponíveis, como trabalho, renda, educação e poder político.

A agenda antirracista é fruto de uma histórica luta de reivindicação de direito. Uma luta que remonta o processo de formação do Brasil, seja colônia, seja monarquia, seja república. Neste último, é possível destacar entidades que lutaram pela melhora da qualidade da vida da população negra e indicaram a existência do racismo como componente impeditivo ao processo de igualdade de acesso a recursos 18 .

A Frente Negra Brasileira atuou entre 1931 e 1937 e conseguiu mobilizar a pequena classe média negra formada por profissionais liberais, profissionais de atividades especializadas, servidores públicos e professores a se dedicar na alfabetização de milhares de pessoas. Igualmente, enxergou na sociedade formas discriminatórias em espaços, sobretudo na educação, cujo dever do Estado com

\footnotetext{
${ }_{17}$ CRENSHAW, Kimberle. Demarginalizing the intersction of race and sex.: a black feminist critique of antidiscrimination doctronine, feminist theory and antiracist politics. The University of Chicago Legal Forum, vol. 140, 1989.

18 VELASCO, Bárbara M. de. Mote à ré...pública- Frente Negra Brasileira: monarquismo paulista no século XX. In Congresso Internacional de História. DOI 10.4025/4cih.pphuem.487. 2009.
} 
Costa, C. L. J., Representatividade negra no executivo municipal: impacto da posição partidária para a eleição de mulheres e homens negros nas prefeituras da Bahia. ODEERE, vol. 6, no. 1 , jan./jun., p. 183-208, 2021. https://doi.org/10.22481/odeere.v6i01.8525

o ensino gratuito ainda não era assumido. Nas escolas particulares, os (as) poucos (as) negros (as) que conseguiam acesso sofriam bullying com 0 intuito que desistissem da vida acadêmica. A FNB, ciente desta triste realidade, assumia 0 compromisso de educar o povo negro ${ }^{19}$.

O Teatro Experimental do Negro é outro exemplo de ativismo da militância negra que legou às novas entidades e à sociedade um conteúdo propositivo sobre a questão racial, permitindo o florescimento da discussão nos ambientes acadêmicos, quando punha em xeque posições acerca da democracia racial e a heteronomia20 do negro, por exemplo21. Figuras como Abdias Nascimento e Alberto Guerreiro Ramos iluminaram o debate de forma qualificada e propositiva. Este último com uma análise arguta sobre o pensamento social brasileiro e o lugar que ele deu ao negro brasileiro e seus descentes. Igualmente, propôs uma democracia multirracial e multicultural, e reivindicou o nigger sum, de modo que as pessoas negras se valorizassem de acordo com as suas características sem pretensão de serem aceitas se camaleando de figuras alusivas ao embranquecimento22.

No final da década de 1970 nos centros industrializados ainda submetidos ao

19 DOMINGUES, Petrônio. Movimento negro brasileiro: alguns apontamentos históricos. In Revista Tempo, vol. 12, n. 13, pp. 100-122. Niteroi. 2007.

20 Hasenbalg, no livro Discriminação e desigualdade raciais no Brasil, publicado em 1979, discute sobre o embate nas Ciências Sociais acerca da autonomia versus heteronomia do negro teve relevo na fase de formação do pensamento social brasileiro acerca das relações raciais. $O$ escrutínio do estado da arte acerca desta temática permitiu a sistematização de duas linhas de fundamento acerca da integração do negro na sociedade no continente americano. A primeira, que tem em Frank Tannenbaum um dos seus principais representantes, entende que o africano escravizado, em virtude da violência sofrida com o sequestro de sua terra natal, a perda de referências culturais, religiosas e familiares consorciadas com o poder absoluto do senhor, tornou-se dependente e infantil. Por outro lado, intelectuais, como Eugene Genovese, acreditaram que o fenômeno da heteronomia conviveu com o processo de reconstrução dos sentidos humanos e civilizatórios a partir do convívio entre os africanos de várias origens da Mãe África e elementos religiosos, no caso dos Estados Unidos, o protestantismo. No Brasil, Hasenbalg destaca o papel das religiões de matriz africana como núcleo social que permitiu a organização do povo negro. Tal esforço comunitário permitiu o sentimento de grupo e a consciência racial. Este processo chamado de autonomia funda-se na percepção do sentido de identidade que permitiu que os africanos e seus descendentes escravizados nas Américas conseguissem se reestruturar, construindo sentidos próprios na nova terra de modo a enfrentar o status de escravos. É pela autonomia que a população negra conseguiu se mobilizar, lutando pela liberdade das diversas formas possíveis, como pela fuga, pela apropriação de conhecimento do colonizador, de modo a usar em benefício da comunidade negra, a exemplo, da jurisdização de cárceres ilegais.

${ }_{21}$ COSTA, 2017.

22 FERES JÚNIOR, JOão. A atualidade do pensamento de Guerreiro Ramos: branquitude e nação. Salvador: CRH, vol. 28, n.73, p. 111-125, 2015 e COSTA, Cleber Lázaro Julião Costa. Racismo no banco dos réus: análise das tensões raciais na esfera dos processos penais em tribunais brasileiros (Tese de Doutorado perante programa pós-graduação em Sociologia-IESP-UERJ). Rio de Janeiro. 2017. 
Costa, C. L. J., Representatividade negra no executivo municipal: impacto da posição partidária para a eleição de mulheres e homens negros nas prefeituras da Bahia. ODEERE, vol. 6, no. 1 , jan./jun., p. 183-208, 2021. https://doi.org/10.22481/odeere.v6i01.8525

corporativismo e a ditatura, alguns sindicatos mobilizavam-se pela luta dos direitos dos trabalhadores. Neste ambiente, O Movimento Unificado contra a Discriminação Racial, o MNUCDR, ganhou as ruas em 07 de julho de 1978 manifestando-se contra o racismo e a lei Afonso Arinos, pois entendia que ela era imprestável para a luta antirracista23.

A mobilização do Movimento Negro não significou que mulheres e homens gozassem do mesmo prestígio. Gonzalez ${ }^{24}$ conta que, no grupo sediado no Rio de Janeiro, havia por parte de alguns militantes um atraso de ideia encarnada em uma visão paternalista e machista que as mulheres não admitiram. Assim, preferiam se reunir separadamente para depois se reunirem com os demais.

A desigualdade no tratamento de gênero estava também presente do próprio movimento. Tal situação fortaleceu a percepção de muitas dessas ativistas quanto à necessidade de refletir a questão do machismo dentro do espaço de luta de modo que tal postura fosse superada.

Na Subcomissão dos Negros, Populações Indígenas, Pessoas Deficientes e Minorias constituída na Comissão da Ordem Social da Assembleia Constituinte de 1987, o protagonismo feminino negro correspondeu como importante ponto de inflexão para o planejamento de políticas públicas que atendessem a população. Com efeito, as discussões e deliberações ali feitas com a presença de Lélia Gonzalez, Helena Theodoro, entre outras especialistas sobre a temática racial contribuíram para o desenho do modelo institucional que deu origem ao Sistema Único de Saúde, a reforma curricular no ensino fundamental, visando dar o devido valor à contribuição da população negra para o desenvolvimento do país nas áreas da educação, economia, sociologia, literatura, entre outras 25 .

Como docentes em sua maioria, compreendiam de forma perspicaz os obstáculos impostos no acesso a recursos para a população negra. Viviam na própria pele as imposições movidas pelo racismo e preconceito. Assim, buscaram

${ }^{23}$ COSTA, Cleber Lázaro Julião Costa. Racismo no banco dos réus: análise das tensões raciais na esfera dos processos penais em tribunais brasileiros (Tese de Doutorado perante programa pósgraduação em Sociologia-IESP-UERJ). Rio de Janeiro. 2017.

24 GONZALEZ, Lélia e HASENBALG, Carlos. Lugar do negro. Rio de Janeiro: Marco Zero. 1981.

25 COSTA, Cleber Lázaro Julião Costa. Racismo no banco dos réus: análise das tensões raciais na esfera dos processos penais em tribunais brasileiros (Tese de Doutorado perante programa pósgraduação em Sociologia-IESP-UERJ). Rio de Janeiro. 2017e SANTOS, Natália Néris da Silva. A voz e a palavra do Movimento Negro na Assembleia Constituinte (1987-1988): um estudo das demandas por direitos (Dissertação/ Programa de Pós-graduação em Direto da FGV/SP). São Paulo. 2015. 
Costa, C. L. J., Representatividade negra no executivo municipal: impacto da posição partidária para a eleição de mulheres e homens negros nas prefeituras da Bahia. ODEERE, vol. 6, no. 1 , jan./jun., p. 183-208, 2021. https://doi.org/10.22481/odeere.v6i01.8525

valorizar a figura da população negra, opondo-se, inclusive, à defesa sobre a influência da heteronomia do negro como elemento determinador de seu lugar social subalterno. O papel das especialistas na temática racial foi de grande importância para a ampliação de direitos sociais à população e deu espaço à justificativa para implementação de políticas afirmativas no futuro.

Entende-se como a agenda antirracista um amplo portfólio de propostas que põem o racismo como elemento estrutural para as desigualdades entre negros (as) e não negros (as). Desigualdades identificadas na área das Ciências Sociais por estudos realizados por ampla gama de pesquisadores ${ }^{26} q u e$ evidenciaram, a partir de estudos quantitativos, a existência de algum elemento presente nas relações sociais que traziam desvantagem para negros (as), mesmo quando eles (as) detinham formação acadêmica, por exemplo, igual ao da pessoa branca. Para além da mobilidade social, essa literatura identificou a letalidade da força policial em escala desproporcional contra jovens pretos e pardos, revelando uma postura seletiva em que a cor da pele se comporta como elemento incriminador ${ }^{27}$.

A luta da mulher negra ia além das reivindicações da mulher branca. Ora, historicamente, a mulher negra é a personagem principal no modelo produtivo herdado da escravidão no Brasil. Desde que as primeiras africanas chegaram no neste país, o trabalho forçado sempre as acompanhou. O fim da escravidão manteve um modelo de sub trabalho materializado na atividade doméstica, cuja equiparação aos demais trabalhos apenas se dev em 2015 pela Lei Complementar 150.

$\mathrm{Na}$ condição de grupo social com maiores índices de trabalho informal, coube à mulher negra, na condição de doméstica, a segurança na mantença familiar, muitas vezes como chefe única de família. Esta condição de luta destoa da maioria das mulheres brancas de classe média, criadas para casar e cujo direito ao trabalho livre apenas deixou de ser condicionado à autorização do marido em

\footnotetext{
26 HANSENBALG, Carlos; SILVA, Nelson do Valle; LIMA, Márcia. Cor e estratificação social. Rio de Janeiro: Contra-Capa. 1999; PAIXÃO, Marcelo et all. Relatório anual das desigualdades raciais no Brasil. Rio de Janeiro: Garamond. 2012.

27 Para uma análise cuidadosa sobre este tema: WEDDERBURN, Rosana Silva Moore. Sobre os discursos que buscam interpretar as razōes que estariam vinculadas à vitimização de jovens negros no Brasil: uma análise dos debates das Comissão Parlamentar de Inquérito Violência contra jovens negros e pobres da Câmara de Deputados (Tese do Programa de Pós-graduação IESP/UERJ). Rio de Janeiro. 2019.
} 
Costa, C. L. J., Representatividade negra no executivo municipal: impacto da posição partidária para a eleição de mulheres e homens negros nas prefeituras da Bahia. ODEERE, vol. 6, no. 1 , jan./jun., p. 183-208, 2021. https://doi.org/10.22481/odeere.v6i01.8525

198928.

Mulheres e homens negros, em sua larga maioria, encontraram-se, ao longo da histórica de pessoas livres no Brasil, na condição de sub cidadania. Invisíveis e apenas úteis aos serviços mais subalternos, a luta por visibilidade é de mais um século e apenas teve fruto pela formação política, a tomada de consciência contrária ao movediço ideal de democracia racial e pelo exercício de liberdade ecoando as suas vozes nas fases em que o país gozou de democracia.

As agendas antirracista e igualdade de gênero consorciam-se à medida que a população negra (mulheres e homens) sente o prejuízo pela sua condição racial ou cor da pele. Mulheres e homens negros sofrem os efeitos do racismo e do machismo. A condição subalterna se encarna pela coisificação dos corpos de várias maneiras: pela sexualização; pela bestalização; pelo subemprego ou pelo óbice a um emprego melhor; pela diferença salarial, apesar de igual formação com o branco; na violência policial; no acesso menos eficiente aos serviços do SUS (sobretudo as mulheres negras, que são as principais clientes do SUS); a prestação educacional em todos os níveis; e pela desvalorização do seu papel em tantas áreas para formação do país.

A dimensão complexa em articular a questão racial com a de gênero corresponde ao desafio de reconhecer a igual importância das reivindicações por esse olhar interseccional, quando reivindicações como questões a exemplo do direito ao aborto, o amplo direito de liberdade sexual e de controle de natalidade, pautas próprias na mobilização feminista agregam-se às demandas mais específicas da população negra feminina, tais como dignidade no acesso aos serviços de saúde, ampliação da rede de creches, dignidade no trabalho, direito ao devido processo legal, entre outros.

A razão para isso é que a pauta feminina é bastante larga e consorcia-se a demandas específicas com a de mulheres negras pela ampla diversidade econômica, intelectual, simbólica que as mulheres independentes de cor/raça se encontram. A visão global na esfera política deve corresponder a um exercício constante para a cidadania, e os partidos políticos deveriam incorporar esse conteúdo de modo atender demandas para uma sociedade mais justa.

28 A mulher deixou de precisar de autorização do marido para trabalhar quando foi revogada o artigo 446 da Consolidação das Leis Trabalhistas (Dec. Lei 5.452/43) pela lei 7.855/1989. 
Costa, C. L. J., Representatividade negra no executivo municipal: impacto da posição partidária para a eleição de mulheres e homens negros nas prefeituras da Bahia. ODEERE, vol. 6, no. 1 , jan./jun., p. 183-208, 2021. https://doi.org/10.22481/odeere.v6i01.8525

Mas essa ideia, cujo conteúdo civilizatório exige uma visão ampliada da cidadania com atendimento à diversidade e às vozes que buscam ser ouvidas na esfera política, ainda no Brasil carece de um fluxo contínuo. Apesar dos avanços, a disposição partidária no país encontra legenda que se opõe a temas importantes para ampliação de direitos e consegue ainda expressiva representatividade política no estado da Bahia e no Brasil.

Vejamos da análise do conteúdo de trechos dos manifestos, diretrizes e posicionamentos extraídos de documentos oficiais e de alguns informes em sites dos partidos cujas publicações foram escrutinizadas. Para tanto, foi feita uma classificação a de zero a quatro. Na posição zero, há postura refratária a qualquer das agendas. Na 01 (um), há alguma manifestação ou progressista, ou para uma ou para outra de forma genérica. Na 02 (dois), há manifestação para ambas, mas de forma genérica. Na 03 (três), há manifestação a favor com contextualização em uma e não na outra. Na 04 (quatro), há posição a favor e com contextualização para ambas. A tabela 5 traz a sistematização dos resultados obtidos.

Tabela 5: Classificação dos partidos pela adesão da temática antirracista e de igualdade de gênero

\section{ESCALA DE ADESÁO}

\section{PARTIDO}

PSL

PTB, DEM, PSB, PSDB, PSD,

REPUBLICANOS, PTC, SDD,

PODEMOS, PP, Patriota

$M D B, R E D E$

PDT, PT, PC do $B$,

CIDADANIA, PV
CLASSIFICAÇÁO29

ZERO

1

2

3

4

TOTAL
QUANTIDADE

1

12

2

5

20

\footnotetext{
29 Legenda:

0-Há postura refratária a qualquer das agendas

1-Há alguma manifestação ou progressista sem citar, ou para uma ou para outra de forma genérica

2-Há manifestação para ambas, mas de forma genérica

3-Há manifestação a favor com contextualização em uma e não na outra

4-Há posição a favor e com contextualização para ambas
} 
Costa, C. L. J., Representatividade negra no executivo municipal: impacto da posição partidária para a eleição de mulheres e homens negros nas prefeituras da Bahia. ODEERE, vol. 6, no. 1 , jan./jun., p. 183-208, 2021. https://doi.org/10.22481/odeere.v6i01.8525

Os documentos partidários não são objeto de publicação a cada eleição, como acontece na União Europeia ${ }^{30}$. Assim, são propostas fruto, na maioria das vezes, do momento de constituição, sofrendo alterações à medida que há algum movimento de adesão a alguma nova causa fruto de propostas em convenções.

Dos partidos, o que trouxe exclusivamente alusões contrárias às pautas antirracista e de igualdade de gênero foi o PSL. Entretanto, esta posição até 2014 não era expressa, pois no documento consolidado pelo Senado Federal, em que constam as diretrizes e propostas não há qualquer referência nesse sentido.

Em verdade, naquela publicação o PSL anotou uma postura crítica à máquina pública, apoio às privatizações e à iniciativa privada como pontos centrais de suas ideias, sem mencionar uma linha sobre gênero ou raça, nem de forma geral. Já no site do partido acessado em 20 de abril de 2021 no item "Diretrizes" consta na letra m "combate aos privilégios decorrentes de quotas" que resultem na divisão do povo, seja em função de gênero, opção sexual, cor, raça ou credo".

A adesão refratária a questões relativas à luta antirracista e a igualdade de gênero ganhou tônus à medida que o PSL acomodou segmentos da sociedade que se opõem a bandeiras de igualdade racial e de defesa da igualdade de gênero. É sintomático que, em 2019, seja de autoria de deputada do partido projeto que eliminaria o critério racial das cotas de universidade e institutos federais. Por sinal, a parlamentar é da bancada baiana, estado com maior população negra no país, e onde as cotas permitiu acesso de várias pessoas.

O PSL elegeu na Bahia 5 prefeitos negros (4 pardos e 1 preto) de 193. Corresponde a 3\%. A filiação a um partido que nada trata sobre a temática racial e gênero do ponto de vista afirmativo e ainda se coloca em posição refratária de forma peremptória levanta a tese de que nem todos os candidatos aderem à agenda antirracista e de igualdade de gênero. Este retrato já registrado pela literatura ${ }^{31}$ ilustra 0 mosaico de percepção acerca da questão racial, quando

\footnotetext{
30 MADEIRA, Rafael Machado e TAROUCO, Gabriel da Silva. Esquerda e direita no Brasil: uma análise conceitual. R. Pós Ci. Soc., n.15, v.8. 2011.

31 Sotero (2016), ao fazer uma pesquisa sobre políticos (as) negros (as) após o Estado Novo explica bem o déficit de representatividade, bem como a qualidade de políticos negros (as) que conseguiram se eleger. Em verdade, a cientista política baiana mostra as dificuldades daqueles (as) que conscientes dos obstáculos impostos pelo racismo, tensionaram nos espaços partidários e na discussão política na esfera competitiva o racismo.
} 
Costa, C. L. J., Representatividade negra no executivo municipal: impacto da posição partidária para a eleição de mulheres e homens negros nas prefeituras da Bahia. ODEERE, vol. 6, no. 1 , jan./jun., p. 183-208, 2021. https://doi.org/10.22481/odeere.v6i01.8525

muitos ainda optam em não discutir de maneira aberta as mazelas do racismo e de sua negação na sociedade brasileira.

A maioria dos partidos possui um discurso generalista acerca das temáticas aqui em discussão. São doze, ou seja, $60 \%$ do conteúdo partidário analisado, que pouco discutiram sobre a questão antirracista ou de igualdade de gênero.

A pauta de gênero é a mais discutida na maioria dos partidos que compõem esse grupo 1. Quando se discute sobre uma dessas temáticas, é a da mulher a mais frequente. Patriota ${ }^{32}$ e PP são a exceção, pois possuem um discurso generalista no todo fazendo alusão a direitos para todas as pessoas sem distinção

A razão para esta maior presença da pauta de gênero tem a ver certamente com a mobilização dos movimentos feministas. Neste sentido, a própria Ciência Política deu, ao longo dos anos, mais espaço a questão da mulher do que a das relações raciais33.

Vale registrar que as mulheres brancas são a maioria das eleitas. Muitas delas são herdeiras do capital político familiar na condição de esposas e filhas de políticos tradicionais no cenário brasileiro. Esta condição favorável as beneficia nas competições eleitorais por trazerem a grife do clã político a que pertence. As mulheres negras, pelo contrário, não possuem esse capital político herdado de familiares. A mobilização política dessas mulheres geralmente começa de baixo, na luta por direito na esfera da dignidade no trabalho, do combate à violência policial nas comunidades, por exemplo. O caminho delas é certamente muito mais difícil o que fica bem evidenciado no baixo número de prefeitas eleitas negras no estado da Bahia, apenas $34 \%$, sendo que nenhuma se autodeclara preta.

Como se vê na tabela 5, os partidos cujo discurso é generalista encontram-se no espectro distribuídos de modo amplo da escala direita-esquerda: PSDB, PP, PTB, DEM, PSD, REPUBLICANOS, PTC, SDD, Patriotas, PODEMOS, PSB.

O estilo de escrita e posicionamento é lacônico. Partidos, como o PTC, por exemplo, trazem no discurso referência a documentos internacionais, a democracia grega, tudo de forma bem genérica, sem qualquer articulação propositiva sobre as raízes das desigualdades e quais escolhas que devem ser

32 O conteúdo do partido Patriota foi analisado a partir do documento do Senado de 2014 quando ainda era PRP. No site (http://patriota51.org.br/projetos), acessado em 25 de abril de 2021, nada foi encontrado.

33 CAMPOS, Luiz Augusto; MACHADO, Carlos, Raça e eleições no Brasil. Porto Alegre: Zouk. 2020. 
Costa, C. L. J., Representatividade negra no executivo municipal: impacto da posição partidária para a eleição de mulheres e homens negros nas prefeituras da Bahia. ODEERE, vol. 6, no. 1 , jan./jun., p. 183-208, 2021. https://doi.org/10.22481/odeere.v6i01.8525

tomadas para a justiça social, termo presente em vários documentos. Assim, deixam pouco evidenciados qual adesão objetiva as causas trazidas pelo Movimento social negro e de igualdade de gênero

Quanto aos partidos que dialogam com as temáticas, é interessante registrar a articulação das ideias por eles trazidas de modo que possa se avaliar o que pode ser objeto de maior reflexão no debate sobre as temáticas aqui trabalhadas.

O MDB, cuja classificação foi 2, entende que a mulher é "agente na promoção social da família"34. Tal discurso ainda sugere a exclusividade dela no seio familiar, prescindindo, pois, do papel do homem, o que parece algo desigual e anacrônico. Esta articulação ambígua sugere a busca por acomodar todos os discursos. A possibilidade de maior espaço às causas está condicionada às circunstâncias e não a uma agenda objetiva.

O Partido dos Trabalhadores, cuja classificação foi 4, trata de discutir a questão de raça e de gênero pela perspectiva da dignidade da pessoa humana, no combate às desigualdades dando ênfase ao caráter redistributivo e pouco a condições relativas ao débito histórico fruto da discriminação contra mulheres e negros como componente estrutural da sociedade brasileira. Este foco na redistribuição talvez justifique a experiência do PT no executivo federal. Apesar de maior êxito na adoção de políticas afirmativas em toda história republicana no Brasil, o Partido dos Trabalhadores poderia ter ido além, inclusive no investimento de novos (as) atores/atrizes do partido que representassem a maioria da população: preta e parda.

No caso da Bahia, o Partido dos Trabalhadores conseguiv eleger 24 políticos (as) negros (as), sendo apenas dois pretos. Um partido que se diz popular precisa urgentemente fomentar maior participação de lideranças negras em cargos majoritários.

O PC do B, que teve nota 4, avança um pouco mais quanto à articulação da pauta, identificando forças conservadoras ao óbice de integrar o negro na sociedade brasileira. Apesar de instrumentalizar o discurso pelas consequências da herança escravista, o que é de certo modo limitador, trata de enxergar o modus operandi das classes dirigentes ao longo da história republicana que,

${ }^{34}$ CF. SENADO FEDERAL. Partidos políticos brasileiro: programas e diretrizes doutrinárias. Brasília. 2014, pp. 41 
Costa, C. L. J., Representatividade negra no executivo municipal: impacto da posição partidária para a eleição de mulheres e homens negros nas prefeituras da Bahia. ODEERE, vol. 6, no. 1 , jan./jun., p. 183-208, 2021. https://doi.org/10.22481/odeere.v6i01.8525

deliberadamente, influenciaram para o aumento do abismo social que vive negros e brancos no Brasil.

O quadro dos documentos analisados demonstra que não há de maneira ampla uma escolha fundada na agenda antirracista para a filiação partidária. No caso da mulher negra, esta adesão tampouco corresponde a um elemento crucial.

Os PT, PC do B, PV, PDT e CIDADANIA foram os que buscaram construir um discurso que contemple tanto a luta antirracista quanto a igualdade de gênero. Entretanto, não articulam a questão racial com a de gênero de modo mais preciso.

Esses partidos não possuem adesão expressiva de prefeitos (as) negros (as) que se elegeram em 2016. Tal situação revela que o discurso aderente à temática racial e de igualdade de gênero não corresponde ao discurso predominante desses(as) candidatos (as).

Prefeitos negros e negras, que na base levantada encontram-se mais na autoclassificação parda, não parecem estar muito preocupados (as) com a discussão das pautas trabalhadas pelo movimento de ativistas negros e negras. A razão para esta constatação é deduzida da pouca representação de eleitos (as) nos partidos que mais trabalham este tema.

A constatação mais evidente é que a expressiva presença de políticos (as) pardos (as) eleitos (as) não está diretamente associada à luta antirracista. Apesar de essa conclusão carecer de mais estudos, sobretudo a partir da análise do conteúdo de campanha, a presença expressiva de partidos pouco afeitos ao histórico de luta, coloca prefeitos e prefeitas negras em uma condição de neutralidade em relação à agenda antirracista e quiçá de igualdade de gênero ou mesmo de oposição.

\section{CONCLUSÃO}

O desenho da distribuição de eleitos (as) da corrida eleitoral de 2016 revela que na Bahia a maioria dos (as) prefeitos autodeclara pertencer ao grupo cor/raça negro, pois representam $52 \%$ da população de chefes de municípios no estado. Este resultado não deve ser, entretanto, razão de comemoração efusiva visto que a realidade social e política brasileira e, em especial, baiana guarda especificidades ilustradas ao longo do desenvolvimento deste texto que 
Costa, C. L. J., Representatividade negra no executivo municipal: impacto da posição partidária para a eleição de mulheres e homens negros nas prefeituras da Bahia. ODEERE, vol. 6, no. 1 , jan./jun., p. 183-208, 2021. https://doi.org/10.22481/odeere.v6i01.8525

demonstram desvantagem para esse grupo.

O destaque inicial a ser lembrado é a maioria dos pardos (as) na população de eleitos (as). A representatividade demográfica deste grupo é encontrada tanto em homens quanto mulheres, o que não acontece entre os (as) pretos (as) quando apenas homens autodeclararam-se deste grupo. Mesmo os homens pretos representam apenas $3 \%$ do total de eleitos, número muito baixo em relação ao contingente populacional do estado.

O número diminuto de pretos e a ausência de pretas prefeitas sugere a existência de uma seleção estruturada na hierarquia racial em que os negros mais escuros são relegados a uma condição pior dos mais claros. Este comportamento impulsiona aos pretos (as) condições mais desfavoráveis e prejudiciais.

Outro elemento importante diz respeito à categoria parda. Apesar da definição objetiva do IBGE que corresponde a pessoas descendentes de preto (a) com branca (o), na prática a definição do pardo tem sido ambígua sobretudo com o advento de políticas afirmativas. Talvez seja necessária a mudança havendo de alguma forma redefinição das categorias cor/raça de modo que as inevitáveis ambiguidades para uma sociedade multirracial como a brasileira sejam mitigadas.

A ausência de mulheres pretas em prefeituras nas eleições de 2016 dá o tom acerca da percepção de exclusão pela perspectiva da Interseccionalidade. Ora, elas encontram-se na base da pirâmide, possuindo péssimos indicadores sociais, o que corresponde a barreiras difíceis de serem ultrapassadas dentro das estruturas partidárias e no próprio processo competitivo em que recursos financeiros e capital social alto são requisitos para a viabilidade do processo eleitoral.

A partir da análise da posição partidária acerca da temática de luta antirracista e de igualdade de gênero, é possível concluir de que essa população de prefeitos (as) negros (as) eleita não esteja de maneira plena em consonância com a agenda antirracista e de igualdade de gênero. Isto porque aderem a partidos cujas proposições acerca dessas duas temáticas é por demais genérica, senão confusa, ou, mesmo, contrária, como é o exemplo do PSL que se opõe às quotas raciais e sexo, por exemplo.

Partidos com defesas genéricas ou ausência de defesas possuem a maioria de mulheres e homens negros eleitos em relação aos partidos em que se encontrou 
Costa, C. L. J., Representatividade negra no executivo municipal: impacto da posição partidária para a eleição de mulheres e homens negros nas prefeituras da Bahia. ODEERE, vol. 6, no. 1 , jan./jun., p. 183-208, 2021. https://doi.org/10.22481/odeere.v6i01.8525

uma contextualização mais qualificada sobre o racismo e as desigualdades raciais por ele imposta e em relação às desigualdades de gênero causadas pelo machismo.

Uma situação não estudada neste trabalho, mas que precisa ser analisada de forma cuidadosa em próximos estudos diz respeito à influência das igrejas neopentecostais no jogo político do estado. Independente da escala partidária direita-esquerda, existe em maior ou menor grau de influência desse segmento social, e no caso da Bahia, uma forte adesão da população negra ao discurso de êxito profissional que tem na política um dos meios para este fim.

A partir dos dados sobre o perfil da população de prefeitos (as) no estado da Bahia nas eleições de 2016 ficou evidente que não há uma relação objetiva de influência das propostas dos partidos com a representatividade negra e feminina. Mulheres e homens eleitos não representam, necessariamente, figuras que tragam em seu discurso posição com base na luta antirracista e de igualdade de gênero. Isto significa uma representação que talvez não coloque como pauta do processo político a questão racial e da mulher negra como elementos relevantes no processo eleitoral.

\section{REFERÊNCIAS:}

ABRANCHES, Sérgio Henrique. Presidencialismo de coalizão: o dilema instrucional brasileiro. Rio de Janeiro: Dados, vol. 31, n.1, 1988.

ALMEIDA, Maria Hermínia Tavares de. Em busca do Centro Perdido. São Paulo: Novo Estudo/CEBRAP. N. 23. 2007.

ARANTES, R. e COUTO, C. Constituição, governo e democracia. São Paulo: RBCS, vol. 2. N. 61. 2006.

BOBBIO, Norberto. Direita e esquerda: razões e significados de uma distinção política. São Paulo: UNESP, 1995.

CARNEIRO, Sueli. Racismo, sexismo e desigualdade no Brasil. São Paulo: Selo Negro. 2011.

CAMPOS, Luiz Augusto; MACHADO, Carlos. A cor dos eleitos: determinantes da subrepresentação política dos não brancos no Brasil. Brasília: Rev. Bras. Ciência Política, n. 16. 2015.

Raça e eleições no Brasil. Porto Alegre: Zouk. 2020.

COSTA, Cleber Lázaro Julião Costa. Racismo no banco dos réus: análise das tensões 
Costa, C. L. J., Representatividade negra no executivo municipal: impacto da posição partidária para a eleição de mulheres e homens negros nas prefeituras da Bahia. ODEERE, vol. 6, no. 1 , jan./jun., p. 183-208, 2021. https://doi.org/10.22481/odeere.v6i01.8525

raciais na esfera dos processos penais em tribunais brasileiros (Tese de Doutorado perante programa pós-graduação em Sociologia-IESP-UERJ). Rio de Janeiro. 2017.

CRENSHAW, Kimberle. Demarginalizing the intersction of race and sex.: a black feminist critique of antidiscrimination doctronine, feminist theory and antiracist politics. The University of Chicago Legal Forum, vol. 140, 1989.

DOMINGUES, Petrônio. Movimento negro brasileiro: alguns apontamentos históricos. In Revista Tempo, vol. 12, n. 13, pp. 100-122. Niteroi. 2007

FERES JÚNIOR, JOão. A atualidade do pensamento de Guerreiro Ramos: branquitude e nação. Salvador: CRH, vol. 28, n.73, p. 111-125, 2015

GIDDENS, Anthony. Para além da esquerda e da direita: o futuro da política radical. São Paulo: UNESP, 1996.

GONZALEZ, Lélia e HASENBALG, Carlos. Lugar do negro. Rio de Janeiro: Marco Zero. 1981.

HANSENBALG, Carlos; SILVA, Nelson do Valle; LIMA, Márcia. Cor e estratificação social. Rio de Janeiro: Contra-Capa. 1999.

HASENBALG, Carlos. Discriminação e desigualdades raciais no Brasil. Rio de Janeiro: Graal. 1979.

HENRIQUES, Ricardo. Silêncio: o canto da desigualdade racial. Rio de Janeiro: Takano. 2003

INSTITUTO BRASILEIRO DE GEOGRAFIA E ESTATÍSTICAS. Estudos sociodemográficos e análises espaciais com a existência de comunidade remanescentes de quilombos. Rio de Janeiro (s/e). 2007.

KINZO, Maria D'Alva G. Partidos, eleições e democracia no Brasil pós 1985. RBCS, vol. 19, n. 54, 2004.

MADEIRA, Rafael Machado e TAROUCO, Gabriel da Silva. Esquerda e direita no Brasil: uma análise conceitual. R. Pós Ci. Soc., n.15, v.8. 2011.

OLIVEIRA, Cloves Luiz Pereira. Estratégias eleitorais de políticos negros no Brasil na era do marketing político. Brasília: Rev. Bras. Ciência Política, n. 21. 2016.

PAIXÃO, Marcelo et all. Relatório anual das desigualdades raciais no Brasil. Rio de Janeiro: Garamond. 2012.

PAIXÃO, Marcelo. A lenda da modernidade encantada: por uma crítica ao pensamento social brasileiro sobre as relações raciais e o projeto de estado-nação. Curitiba: CRV. 2014.

PRETRUCCELLI, José Luís e SABOIA, Ana Lúcia (orgs). Características étnico-raciais da população: classificação e identidades. Rio de Janeiro: s/e (IBGE). 2013.

SACCHET, Tereza. Partidos políticos e (sub) representação feminina: um estudo 
Costa, C. L. J., Representatividade negra no executivo municipal: impacto da posição partidária para a eleição de mulheres e homens negros nas prefeituras da Bahia. ODEERE, vol. 6, no. 1 , jan./jun., p. 183-208, 2021. https://doi.org/10.22481/odeere.v6i01.8525

sobre recrutamento legislativo e financiamento de campanhas. In PAIVA, Denise (org.) Mulheres, política e poder. Goiânia: Cânone. 2011 pp. 159-186

SANTOS, Natália Néris da Silva. A voz e a palavra do Movimento Negro na Assembleia Constituinte (1987-1988): um estudo das demandas por direitos (Dissertação/ Programa de Pós-graduação em Direto da FGV/SP). São Paulo. 2015.

SENADO FEDERAL. Partidos políticos brasileiro: programas e diretrizes doutrinárias. Brasília. 2014.

SOTERO, Edilza Correia. Negros candidatos e candidatos negros: partidos políticos e campanhas eleitorais na cidade São Paulo após o fim do Estado Novo. São Paulo: Revista do Programa de Pós-graduação em Sociologia da USP, n. 1, vol. 23. 2016.

VELASCO, Bárbara M. de. Mote à ré...pública- Frente Negra Brasileira: monarquismo paulista no século XX. In Congresso Internacional de História. DOI 10.4025/4cih.pphuem.487 . 2009.

WEDDERBURN, Rosana Silva Moore. Sobre os discursos que buscam interpretar as razões que estariam vinculadas à vitimização de jovens negros no Brasil: uma análise dos debates das Comissão Parlamentar de Inquérito Violência contra jovens negros e pobres da Câmara de Deputados (Tese do Programa de Pósgraduação em Sociologia-IESP/UERJ). Rio de Janeiro. 2019

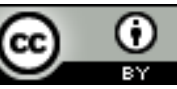

This work is licensed under a Licence Creative Commons Attribution 4.0 International License.

(c)

Este trabalho está licenciado com uma Licença Creative Commons - Atribuição 4.0

Internacional. 